\title{
Enhanced in vitro invasiveness of ovarian cancer cells through up-regulation of VEGF and induction of MMP-2
}

\author{
ALI ZHANG $^{1 *}$, LI MENG $^{1 *}$, QUNSHENG WANG $^{2}$, LING XI $^{1}$, GANG CHEN $^{1}$, SHIXUAN WANG $^{1}$, \\ JIANFENG ZHOU ${ }^{1}$, YUNPING $\mathrm{LU}^{1}$ and DING MA ${ }^{1}$ \\ ${ }^{1}$ Cancer Biology Center, Tongji Hospital; ${ }^{2}$ Department of Nephrology, Xiehe Hospital, Tongji Medical College, \\ Huazhong University of Science and Technology, Wuhan, P.R. China
}

Received November 1, 2005; Accepted January 3, 2006

\begin{abstract}
Vascular endothelial growth factor (VEGF) has been identified to be important in tumor angiogenesis, which is essential for the growth, invasion, and metastasis of solid tumors. The aim of this study was to determine the effect of VEGF overexpression on the invasion of human epithelial ovarian cancer cells in vitro and the possible mechanism involved. The $\mathrm{VEGF}_{165}$ cDNA was transfected into ovarian tumor cell lines CAOV3 and COC1 to promote the expression of VEGF. The VEGF expression and matrix metalloproteinase (MMP)-2 activity were examined by RT-PCR, Western blot analysis and gelatin zymography. A modified Boyden chamber assay was used to test tumor cell invasion in vitro. All cells overexpressing VEGF displayed an enhanced in vitro invasiveness through Matrigel-coated filters with Boyden chamber invasion assay. MMP-2 mRNA and protein were significantly increased during VEGF $_{165}$ cDNA transfection; MMP-2 activity was also increased. The invasion property of ovarian cancer cells was abrogated with VEGF neutralizing antibody. Our data indicated that the expression of VEGF gave impetus to the in vitro invasion of ovarian cancer cells by stimulating the production and functional activities of MMP-2, which may be a key component of VEGF in promoting ovarian cancer cell invasion. VEGF may constitute a novel therapeutic target for antiangiogenic cancer therapy.
\end{abstract}

Correspondence to: Dr Ding Ma, Cancer Biology Center, Tongji Hospital, Tongji Medical College, Huazhong University of Science and Technology, 1095 Jiefang Avenue, Wuhan, Hubei 430030, P.R. China

E-mail:dma@tjh.tjmu.edu.cn

${ }^{*}$ Contributed equally

Abbreviations: VEGF, vascular endothelial growth factor; MMPs, matrix metalloproteinases

Key words: ovarian carcinoma, vascular endothelial growth factor, matrix metalloproteinase, invasion

\section{Introduction}

Epithelial ovarian carcinoma is the leading cause of death from gynecologic malignancy and causes 100,000 deaths annually in women worldwide. Additionally, most patients have disseminated intraperitoneal spread at the time of diagnosis, and approximately $40 \%$ of women with advanced ovarian cancer have lymph node metastasis. However, the mechanism of metastasis remains unclear.

VEGF is a multifunctional peptide that elicits numerous cellular effects pertinent to the metastasis process including the regulation of epithelial cell proliferation, modulation of angiogenesis, and synthesis of extracellular matrix proteins (matrix metalloproteinases, MMPs). The expression of VEGF has been reported to correlate with the malignancy of different tumor types, such as gliomas, prostate cancer, pancreatic adenocarcinoma, renal cell carcinoma, squamous cell carcinomas, bladder cancer, non-small cell lung cancer, hepatic carcinoma and colorectal cancer (1-4). Recent studies have shown that the elevated serum VEGF levels and increased VEGF expression in epithelial ovarian tumor were associated with the development, invasion and metastasis of ovarian tumors $(5,6)$. VEGF $_{165}$ overexpression stimulated angiogenesis and induced cyst formation and macrophage infiltration in human ovarian cancer engrafts (7). However, there have been no direct studies showing that the overexpression of VEGF promotes ovarian tumor metastasis.

Tumor metastasis requires that tumor cells first attach to the extracellular matrix through cell membrane receptors that mediate binding to matrix components, such as laminin, collagen and fibronectin. Subsequently, localized proteolysis initiated by tumor cells results in the degradation of matrix (8). Two families of proteases, the plasminogen activator/ plasmin system of serine proteases and MMPs, have been implicated in these processes (9). Ovarian cancer cells express MMP-2 and MMP-9, and their increased expression is associated with their invasive and metastatic potential (10-13). Furthermore, treatment administered to animals harboring ovarian cancer xenografts with synthetic MMP inhibitors reduced the tumor burden (14). It has been shown that stromal MMP-9 contributes to the malignant behavior of ovarian cancers by promoting neovessel sprouting and tumor growth (15), and the fact that accelerated SMC migration treated by VEGF could be blocked by MMP inhibition in 
Matrigel indicated that MMPs may contribute to SMC migration in angiogenesis (16). Further results showed that minocycline inhibited VEGF-induced smooth muscle cell migration, including inhibition of MMP-9 mRNA transcription and protein activities, and down-regulating ERK1/2 and PI3K signaling pathways (17). These findings suggest an interplay between VEGF and MMP-9. However, scarce data are available on the potential relationship between VEGF and MMP-2 in the invasion of ovarian cancer.

In the present study, we investigated the correlation between VEGF and MMP-2 and evaluated their potential effects on the invasion capacity of ovarian tumor cell lines in vitro to clarify the role of VEGF in metastasis and the underlying mechanism.

\section{Materials and methods}

Cell culture and reagents. The epithelial ovarian cancer cell lines $\mathrm{CaOV} 3$ and $\mathrm{COC} 1$, obtained from the American Type Culture Collection, were grown in DMEM or RPMI-1640 with $10 \%$ heat-inactivated fetal bovine serum and penicillinstreptomycin (50 units/ml-50 $\mu \mathrm{g} / \mathrm{ml}$ ). NIH 3T3 cells, kindly provided by Dr Lijun Xin (Center of Immunology, Wuhan, China), were cultured in RPMI-1640 with $10 \%$ heat-inactivated fetal bovine serum and penicillin-streptomycin. Cells were grown at $37^{\circ} \mathrm{C}$ in a humidified atmosphere $\left(5 \% \mathrm{CO}_{2}, 95 \%\right.$ air $)$.

$\mathrm{VEGF}_{165} \mathrm{cDNA}$ was a generous gift from Dr Jianguo Ma (Fox Chase Cancer Center, USA). Trizol reagent was purchased from Gibco. Dosper liposomal transfection reagent was obtained from Boehringer-Mannheim. Oligonucleotides were acquired from Shenggong Biotechnology (Shanghai, China). Anti-MMP-2 goat IgG and anti-VEGF rabbit IgG were purchased from Santa Cruz Biotechnology. Rabbit anti-goat IgG and goat anti-rabbit alkaline phosphatase conjugate were obtained from Zhongshan Biotechnology (Beijing, China). Growth factor-reduced Matrigel was purchased from BectonDickinson. The $8 \mu \mathrm{m}$-pore PET membrane and 48 -well invasion plates were provided by Professor Feili Gong (Center of Immunology, Wuhan, China). Cell culture reagents and other chemical materials were purchased from Sigma.

Transfection of tumor cells with VEGF ${ }_{165}$ cDNA. Bacteria DH5 $\alpha$ transformed with VEGF $_{165}$ cDNA were amplified, and the plasmid $\mathrm{VEGF}_{165} \mathrm{cDNA}_{\text {was }}$ prepared and purified according to the Molecular Cloning: A Laboratory Manual. The prepared plasmid was digested with restriction enzyme BamHI, EcoRI at $37^{\circ} \mathrm{C}$ for $2 \mathrm{~h}$, then electrophoresis was performed. Ovarian tumor cells were transfected using Dosper Liposomal Transfection Reagent according to the manufacturer's instructions. PcDNA3.1 vector was transfected as an empty vector control.

Preparation of conditioned media. Conditioned media were prepared by incubating subconfluent cells in 24-well plates for $24 \mathrm{~h}$ in serum-free DMEM or RPMI-1640. Cells were trypsinized and counted. Conditioned media were harvested and clarified by centrifugation, and stored at $-80^{\circ} \mathrm{C}$.

RT-PCR VEGF and MMP-2. Total RNA was extracted from the cell monolayer using the Trizol reagent kit following the
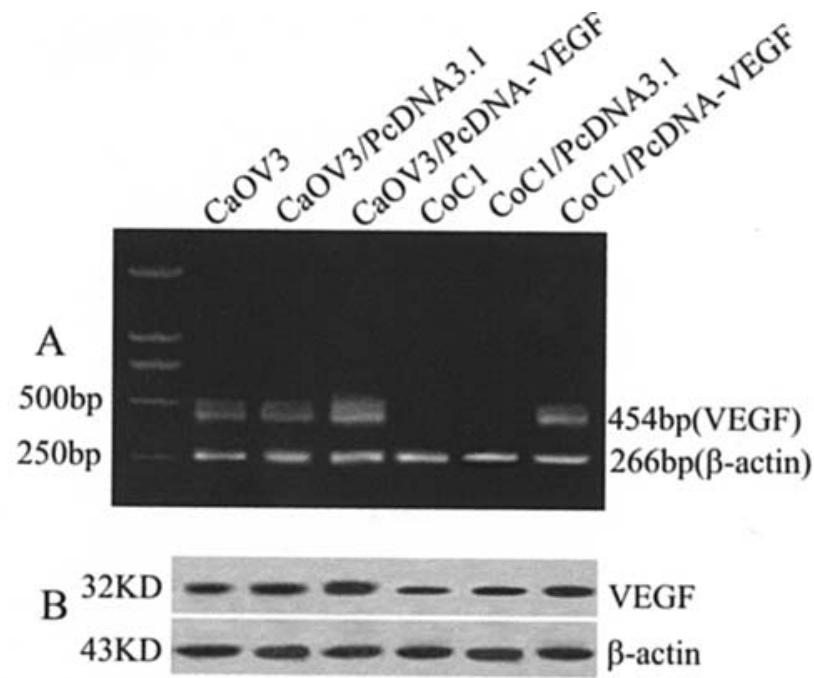

Figure 1. RT-PCR and Western blot analysis of VEGF expression in ovarian cancer cells, transfected with either VEGF165 cDNA or empty vector PcDNA3.1 mRNA of ovarian cancer cells $\mathrm{CaOV} 3$ and $\mathrm{CoC} 1$, were acquired and then demonstrated by RT-PCR using primers specific for VEGF and $\beta$-actin (A). Whole cell lysates were detected by Western blot analysis with specific antibodies against VEGF or $\beta$-actin (B).

manufacturer's instructions. For reverse transcription (RT)PCR analyses, $2 \mu \mathrm{g}$ RNA was treated with RNase-free DNase, and cDNA was obtained using Moloney murine leukemia virus reverse transcriptase. For semiquantitative PCR, $5 \mu \mathrm{l}$ cDNA was amplified by PCR using the specific primers: VEGF (18) (454 bp), 5'-GGA TGT CTA TCA GCG CAG CAC - 3 ' and 5'-TCA CCG CCT CGG CTT GTC ACA TC-3'; MMP-2 (19) (580 bp), 5'-GTG CTG AAG GAC ACA CTA AAG AAG A-3' and 5'-TTG CCA TCC TTC TCA AAG TTG TAG G- 3'; ß-actin (20) (266 bp), 5'-AGC AGA GAA TGG AAA GTC AAA-3' and 5'-ATG CTG CTT ACA TGT CTC GAT-3'. PCR conditions were followed by 30 cycles for VEGF or MMP-2 consisting of $94^{\circ} \mathrm{C}$ for $1 \mathrm{~min}$, $61^{\circ} \mathrm{C}$ for $2 \mathrm{~min}, 72^{\circ} \mathrm{C}$ for $2 \mathrm{~min}$ or $94^{\circ} \mathrm{C}$ for $45 \mathrm{sec}, 59^{\circ} \mathrm{C}$ for $1 \mathrm{~min}$ and $72^{\circ} \mathrm{C}$ for $90 \mathrm{sec}$, and a final elongation step of $72^{\circ} \mathrm{C}$ for $5 \mathrm{~min}$. The reaction products were visualized by subjecting them to electrophoresis in $1.5 \%$ agarose in $1 \mathrm{X}$ TBE buffer containing $0.5 \mu \mathrm{g} / \mathrm{ml}$ ethidium bromide.

Western blot analysis. Aliquots of the conditioned media adjusted to the same number of cells were boiled for $5 \mathrm{~min}$ in sample buffer. Proteins were resolved by electrophoresis in $10 \%$ sodium dodecyl sulfate-polyacrylamide gels (SDSPAGE) and transferred to nitrocellulose membranes. The membranes were incubated in blocking solution containing $5 \%$ nonfat dry milk and $0.05 \%$ Tween-20 in TBS (TBS-T) at room temperature for $1 \mathrm{~h}$ to inhibit nonspecific binding. The membranes were then incubated with the primary antibody [anti-VEGF polyclonal IgG (1:1000) and anti-MMP-2 polyclonal $\operatorname{IgG}(1: 1000)]$ at $4^{\circ} \mathrm{C}$ overnight. After 3 washes with TBS-T, the membrane was incubated with alkaline phosphatase-conjugated secondary antibody at $37^{\circ} \mathrm{C}$ for $1 \mathrm{~h}$. NBT/BCIP was used to detect the hybridization protein.

Gelatin zymography. Aliquots (5-10 $\mu 1)$ of conditioned media were analyzed for proteinase activity by substrate gel 

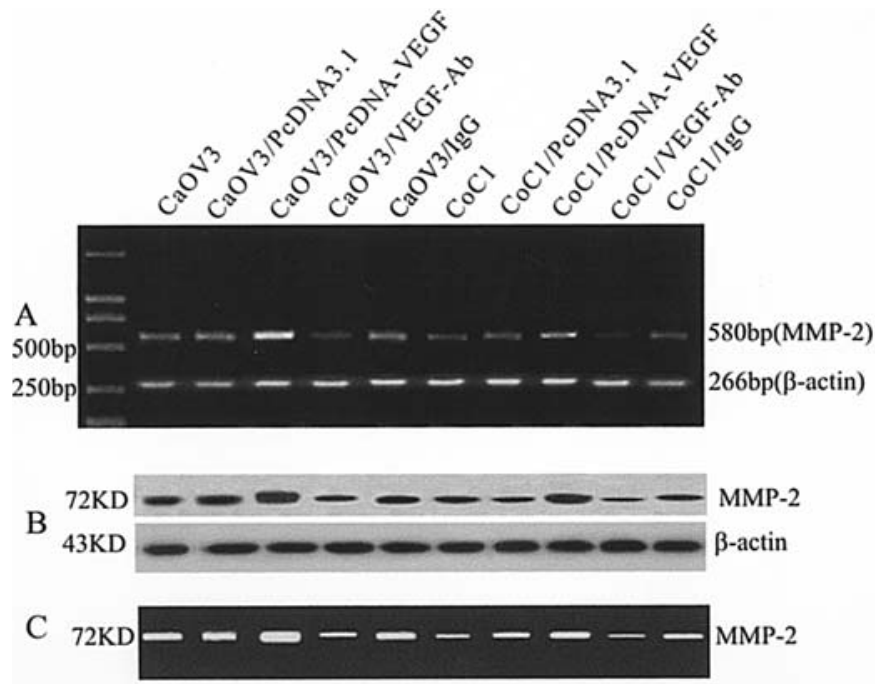

Figure 2. RT-PCR (A), Western blot analysis (B) and zymography (C) of MMP-2 expression and activity in ovarian cancer cells transfected with

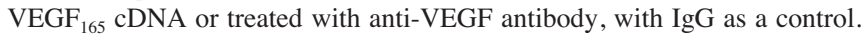
Up-regulation of MMP-2 expression was detected in both $\mathrm{CaVO} 3$ and $\mathrm{CoC} 1$ cells transfected with $\mathrm{VEGF}_{165}$ cDNA. Specific VEGF antibody treatment down-regulates the expression of MMP-2 in both $\mathrm{CaVO} 3$ and $\mathrm{CoC} 1$ cells.

zymography as described previously. Briefly, equal amounts of proteins were separated in $10 \%$ SDS-PAGE co-polymerized with $0.1 \%$ gelatin. After electrophoresis, the gels were rinsed twice in $2.5 \%$ Triton $\mathrm{X}-100$ for $30 \mathrm{~min}$ at room temperature, then incubated at $37^{\circ} \mathrm{C}$ for $20 \mathrm{~h}$ in $1.5 \mathrm{M} \mathrm{NaCl}, 50 \mathrm{mM}$ Tris- $\mathrm{Cl}$, and $10 \mathrm{mM} \mathrm{CaCl}_{2}$ (pH 7.5). The gels were stained with $0.5 \%$ Coomassie blue R250 and destained in 50\% methanol and $10 \%$ acetic acid in $\mathrm{H}_{2} \mathrm{O}$ (21).

In vitro invasion assay. In vitro invasion assay was performed according to a published protocol with some modifications (22). Invasion was measured using 48-well units with $8 \mu \mathrm{m}$ porosity polycarbonate filters. The upper side of the filter was coated with Matrigel matrix $120 \mu \mathrm{g} /$ well, incubated at $37^{\circ} \mathrm{C}$ for $3 \mathrm{~h}$ and left to dry at room temperature overnight. The Matrigel matrix was rehydrated with $100 \mu 1$ of pre-warmed DMEM for $2 \mathrm{~h}$ at room temperature. Cells were harvested, washed and suspended in DMEM in the absence or presence of $50 \mathrm{nM}$ VEGF $\mathrm{mAb}$ at $7.5 \times 10^{3} /$ well. The lower chambers were filled with serum-free conditioned media of NIH 3 T3. Noncoated membrane inserts served as controls in the invasion assay. Following incubation for $18 \mathrm{~h}$ at $37^{\circ} \mathrm{C}$ under standard culture conditions, noninvasive cells were removed from the upper surface of the membrane, followed by fixation with $70 \%$ methanol at room temperature for $45 \mathrm{~min}$ and stained with hematoxylin. All experiments were completed in triplicate, and at least 10 fields were counted.

Image and statistical analysis. Photographs were scanned, and the intensity of bands with background subtractions was measured using Leica Q550 IW Image Analysis software. The expression of VEGF and MMP-2 was indirectly reflected by the ratio of $\beta$-actin level. All experiments were repeated at least 3 times, and all results were expressed as means \pm SEM, and assessed using the unpaired two-tailed Student's t-test ( $\mathrm{p}$-values $<0.05$ were considered significant).

\section{Results}

VEGF expression in stably transfected ovarian tumor cell lines. To determine the role of VEGF overexpression in tumor progression, both $\mathrm{CaOV} 3$ and $\mathrm{CoC} 1$ cells were transfected with $\mathrm{VEGF}_{165}$ cDNA. RT-PCR analysis of total RNA from subconfluent culture cells showed a significant increase of VEGF expression in $\mathrm{CaOV} 3$ and $\mathrm{CoC} 1$ cell lines after transfection (CaOV3/PcDNA-VEGF $0.98 \pm 0.05$ vs. control $0.84 \pm 0.03, \mathrm{p}<0.05$; CoC1/PcDNA-VEGF $0.87 \pm 0.06$ vs. control $0.62 \pm 0.04, \mathrm{p}<0.05)$ (Fig. 1A). This modulation of VEGF expression was confirmed by measuring the VEGF protein using Western blot analysis. As shown in Fig. 1B, the level of VEGF protein in conditioned media was in accordance with the expression of VEGF mRNA in tumor cells (CaOV3/PcDNA-VEGF 24.4 \pm 1.2 vs. control 18.3 \pm 0.7 , $\mathrm{p}<0.05$; CoC1/PcDNA-VEGF $20.8 \pm 0.8$ vs. control $15.8 \pm 0.6$, $\mathrm{p}<0.05)$.

Overexpression of VEGF enhances the production and activity of MMP-2. To determine how VEGF promotes ovarian cancer cell invasion, several experiments were performed to study the effect of VEGF on production of MMP-2 protease secreted by tumor cells, which could degrade the Matrigel matrix for invasion through this physical barrier filter. As assessed by RT-PCR and Western blot analysis, the expression of MMP-2 mRNA and protein increased simultaneously in both $\mathrm{CaOV} 3$ and $\mathrm{CoC} 1$ cells transfected with $\mathrm{VEGF}_{165}$ cDNA (Fig. 2A and B). We then screened the change of extracellular matrix-degrading proteinase activities. Conditioned media from ovarian tumor cells were tested for MMP-2 activity using zymography. Regions of proteolytic activity were visualized as clear zones against a blue background. The increased expression of MMP-2 mRNA and protein correlated with enhanced collagenase activity. The MMP-2 activities of transfected $\mathrm{CaOV} 3$ and $\mathrm{CoC} 1$ cells were detected as $25.3 \pm 1.2$ and $18.9 \pm 0.9$, respectively, while only $19.3 \pm 0.8$ and $9.8 \pm 0.5$ were found in nontransfected cells (Fig. 2C). There was a significant difference between

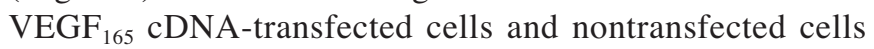
$(p<0.05)$. The study showed that VEGF transfection increased both production and activity of MMP-2 in ovarian cancer cells.

VEGF overexpression correlates with tumor invasion in vitro. To further investigate the role of VEGF in tumor cell invasion, a modified Boyden chamber assay was used to test tumor cell invasion in vitro. The invasive activity was determined by measuring the ability of tumor cells to migrate through Matrigel-coated filters. We found that the $\mathrm{VEGF}_{165}$ cDNA-transfected cells showed VEGF overexpression and had high invasive activity in vitro, whereas the nontransfected cells displayed low levels of VEGF expression and had poor ability to traverse the Matrigel barrier. The mean percentage of transfected tumor cells was higher than that of nontransfected cells (CaOV3/PcDNA-VEGF 42.5 \pm 4.1 vs. control 24.7 $\pm 1.9, \mathrm{p}<0.05$; CoC1/PcDNA-VEGF 26.8 \pm 2.4 vs. control $8.6 \pm 1.1, \mathrm{p}<0.05$ ) (Fig. 3 and Table I). Overall, a 2 - to 4-fold increase of invasive activity was induced in

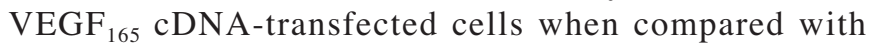



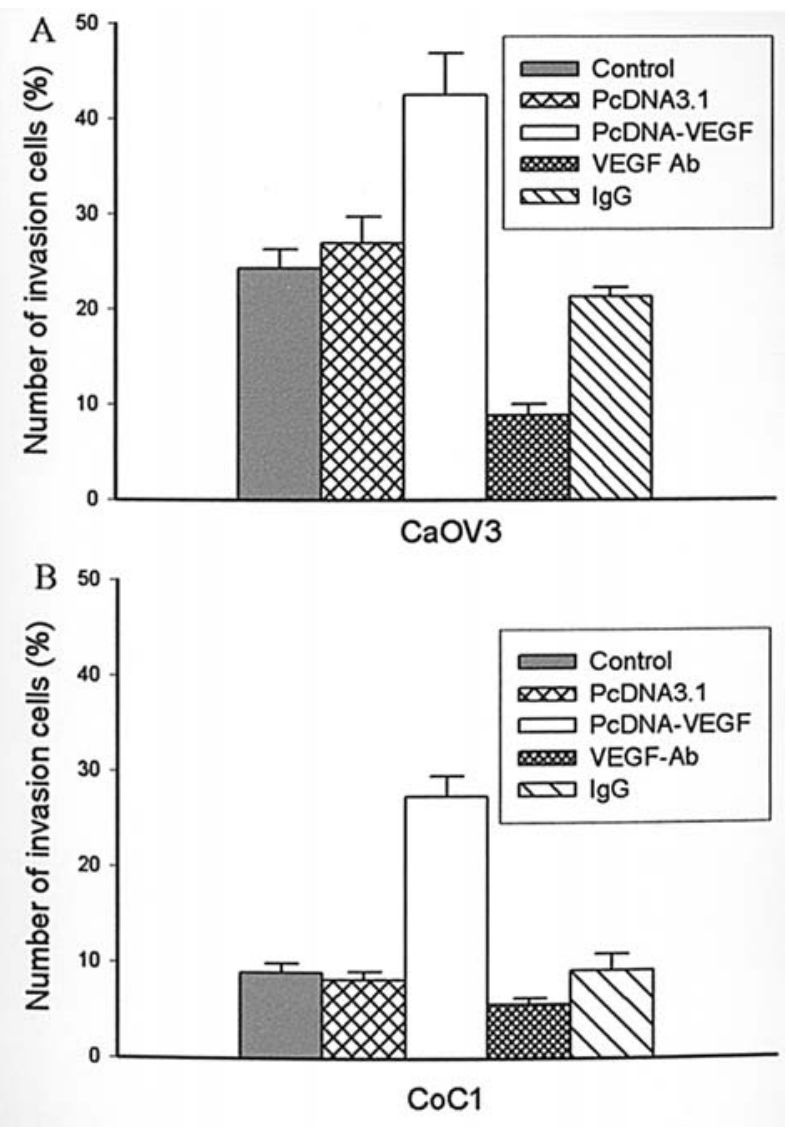

Figure 3. Invasion assays were carried out in the Matrigel-coated membrane inserts. Noncoated membrane inserts were seeded to serve as controls. The obvious ability of traversing the Matrigel-coated membrane was detected in

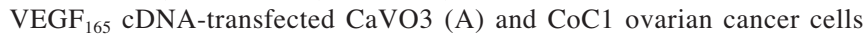
when compared to nontransfected cells or empty vector-transfected cells. Data are expressed as the percentage of invasion, the ratio of cells invading through the Matrigel matrix-coated inserts compared to uncoated control inserts.

nontransfected cells. These results demonstrated that VEGF played an important role in ovarian cancer cell invasion. VEGF may promote ovarian cancer cells to secrete MMP-2 protease, which accelerates tumor cell invasion by degrading the extracellular matrix.

Effect of anti-VEGF antibody administration on expression and activity of MMP-2 invasiveness of ovarian cancer cells in vitro. Previous reports demonstrated that a monoclonal antibody against VEGF inhibited S.C. tumor formation in a dose- and time-dependent manner and reduced the number and size of liver metastases (23). To confirm that VEGF expression and MMP-2 activity are functionally associated, anti-VEGF monoclonal IgG was administered with $\mathrm{CaOV} 3$ and $\mathrm{CoC} 1$ ovarian cancer cells. We found that antibody treatment reduced the expression and activity of MMP-2 (Fig. 2). These findings suggested that VEGF expression and MMP-2 activity are physiologically linked in ovarian tumor cells. Accordingly, in vitro invasion of the two cell lines was reduced significantly when treated with anti-VEGF

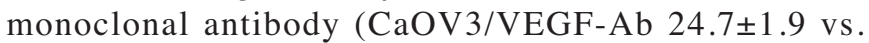
control 10.2 \pm 0.7 ; CoC1/VEGF-Ab 8.6 \pm 1.1 vs. control 5.4 \pm 0.3 ) (Fig. 3 and Table I).

\section{Discussion}

There is evidence of a relationship between VEGF and MMPs in tumor progression. Herein we showed that VEGF induced the release of biologically active MMP-2 in the culture medium of ovarian tumor cells. This was associated with tumor invasion, providing direct evidence that VEGF is associated with the release of MMP-2 by ovarian tumor cells (24).

Vascular endothelial growth factor is a multifunctional polypeptide growth factor that plays an important role in tumor angiogenesis and invasion. Previously it has been indicated that there is a correlation between the expression of VEGF and tumor cell migration and invasion $(27,28)$. In serous ovarian cystadenocarcinomas, VEGF expression was associated with its malignant behavior $(6,25,26)$. However, no direct evidence has been provided as to how VEGF is responsible for promoting ovarian tumor metastasis. In the current study, we transfected $\mathrm{VEGF}_{165}$ cDNA into ovarian cancer cells to regulate the expression of VEGF. The data showed that endogenous VEGF mRNA and protein levels increased interdependently in cultured cells after being transfected. In line with previous data showing that human squamous cell carcinomas SCC-13 transfected with VEGF164 in the sense (SCC/VEGF+) vector invaded the surrounding tissue (29), we found there was an obvious enhancement in vitro invasiveness through Matrigel-coated filters in VEGF-transfected $\mathrm{CaOV} 3$ and $\mathrm{CoC} 1$ cells compared with nontransfected groups. Furthermore, the invasion ability of tumor cells was reduced after receiving VEGF monoclonal antibody administration in our study. This finding suggests that VEGF itself has a critical role in the regulation of ovarian tumor invasion.

Proteolysis may be another important factor for ovarian cancer metastasis (13-15). One family of proteases, MMPs, could be influenced at the transcriptional level by several different factors, including hormones, growth factors,

Table I. In vitro invasion ability of ovarian cancer cells (\%).

Tranfects or treatments

\begin{tabular}{lcccrr}
\cline { 2 - 5 } Cell line & Control & PcDNA3.1 & PcDNA-VEGF & VEGF-Ab & \multicolumn{1}{c}{ IgG } \\
\hline CaOV3 & $24.7 \pm 1.9$ & $26.6 \pm 2.1$ & $42.5 \pm 4.1^{\mathrm{a}}$ & $10.2 \pm 0.7^{\mathrm{a}}$ & $21.5 \pm 2.3$ \\
$\mathrm{CoC} 1$ & $8.6 \pm 1.1$ & $7.9 \pm 1.4$ & $26.8 \pm 2.4^{\mathrm{a}}$ & $5.4 \pm 0.3^{\mathrm{a}}$ & $9.4 \pm 1.2$ \\
\hline
\end{tabular}

${ }^{\mathrm{a}} \mathrm{p}<0.05$ compared with control. 
oncogenes and cytokines. Some reports suggest that there is interaction between VEGF and MMP expression. It was demonstrated that VEGF increased the release of gelatinase A in microvascular endothelial cells in vitro, and up-regulated MMP-2 expression in brain tumor cells $(30,31)$. In ovarian cancer, the MMP-VEGF relationship is indicated by several observations. Huang et al, using in vivo models of ovarian carcinoma, found an important role for macrophage-derived MMP-9 in angiogenesis and ovarian tumor growth (15). However, a functional association between VEGF expression and the activity of MMP-2 has not been demonstrated.

The present study showed that the expression and activity of MMP-2 were increased after VEGF stimulation. There may be several possible mechanisms of action of VEGF, including directly stimulating MMP-2 release from tumor cells, and activating other factors involved in MMP-2 release. Additional studies are necessary to clarify this phenomenon. It should be noted that VEGF stimulates the expression of interstitial collagenase at the mRNA and protein levels in human umbilical vein endothelial cells, but no induction was seen in the expression of other MMP members, including MMP-2 $(32,33)$. The differences may come from the cell and tissue specification or interaction with MMPs and their inhibitors the TIMPs. We also found that the induction of MMP-2 by VEGF cDNA transfection in the two ovarian cancer cell lines correlated with great invasive potential. An inhibition of VEGF activity with a neutralizing antibody significantly decreased invasion in both cell lines. Therefore, our results suggested that VEGF could play an important role in invasion processes through the induction of proteolytic response in tumor cells expressing MMP-2.

In conclusion, our results suggested that the overexpression of VEGF correlated with the in vitro invasiveness of ovarian cancer cells. Induction and activity of MMP-2 stimulated by VEGF could be the main mechanism by which VEGF gives impetus to the invasion of ovarian cancer cells. Our results emphasized the importance of induction of MMP-2 by VEGF during tumor metastasis, and VEGF may constitute a novel therapeutic target for antiangiogenic cancer therapy.

\section{Acknowledgements}

This work was sponsored by grants from the National Science Foundation of China (no. 30025017) and '973' Program of China (no. 2002CB513100).

\section{References}

1. Lee JC, Chow NH, Wang ST and Huang SM: Prognostic value of vascular endothelial growth factor expression in colorectal cancer patients. Eur J Cancer 36: 748-753, 2000

2. Shih CH, Ozawa S, Ando N, Ueda M and Kitajima M: Vascular endothelial growth factor expression predicts outcome and lymph node metastasis in squamous cell carcinoma of the esophagus. Clin Cancer Res 6: 1161-1168, 2000.

3. Shang ZJ, Li JR and Li ZB: Circulating levels of vascular endothelial growth factor in patients with oral squamous cell carcinoma. Int J Oral Maxillofac Surg 31: 495-498, 2002.

4. Linderholm BK, Lindh B, Beckman L, et al: Prognostic correlation of basic fibroblast growth factor and vascular endothelial growth factor in 1307 primary breast cancers. Clin Breast Cancer 4: 340-347, 2003.

5. Qi SY: Expression of vascular endothelial growth factor and microvessel density in ovarian tumor. Ai Zheng 229: 320-323, 2003.
6. Brustmann $\mathrm{H}$ and Naude S: Vascular endothelial growth factor expression in serous ovarian carcinoma: relationship with high mitotic activity and high FIGO stage. Gynecol Oncol 84: 47-52, 2002.

7. Duyndam MC, Hilhorst MC, Schluper HM, et al: Vascular endothelial growth factor-165 overexpression stimulates angiogenesis and induces cyst formation and macrophage infiltration in human ovarian cancer xenografts. Am J Pathol 160: 537-548, 2002 .

8. Ma D, Gerard RD, Li XY, Alizadeh H and Niederkorn JY: Inhibition of metastasis of intraocular melanomas by adenovirusmediated gene transfer of plasminogen activator inhibitor type 1 (PAI-1) in an athymic mouse model. Blood 90: 2738-2746, 1997.

9. Liotta LA, Tryggvason K, Garbisa S, Hart I, Foltz CM and Shafie S: Metastasis potential correlates with enzymatic degradation of basement membrane collagen. Nature 284: 67-68, 1980 .

10. Shimada T, Nakamura H, Yamashita K, et al: Enhanced production and activation of progelatinase A mediated by membrane-type 1 matrix metalloproteinase in human oral squamous cell carcinomas: implications for lymph node metastasis. Clin Exp Metastasis 18: 179-188, 2000.

11. Kawata R, Shimada T, Maruyama S, Hisa Y, Takenaka H and Murakami Y: Enhanced production of matrix metalloproteinase-2 in human head and neck carcinomas is correlated with lymph node metastasis. Acta Otolaryngol 122: 101-106, 2002.

12. Moore DH, Allison B, Look KY, Sutton GP and Bigsby RM: Collagenase expression in ovarian cancer cell lines. Gynecol Oncol 65: 78-82, 1997.

13. Sakata K, Shigemasa K, Uebaba Y, Nagai N and Ohama K: Expression of matrix metalloproteinases- 2 and -9 by cells isolated from the peritoneal fluid of women with ovarian carcinoma. Acta Cytol 46: 697-703, 2002.

14. Schmalfeldt B, Prechtel D, Harting K, et al: Increased expression of matrix metalloproteinases MMP-2, MMP-9 and the ukokinase type plasminogen activator is associated with progression from benign to advanced ovarian cancer. Clin Cancer Res 7: 2396-2404, 2001.

15. Huang S, Van Arsdall M, Tedjarati S, McCarty M, Wu W, Langley R and Fidler IJ: Contributions of stromal metalloproteinase-9 to angiogenesis and growth of human ovarian carcinoma in mice. J Natl Cancer Inst 94: 1134-1142, 2002.

16. Wang H and Keiser JA: Vascular endothelial growth factor upregulates the expression of matrix metalloproteinases in vascular smooth muscle cells: role of flt-1. Circ Res 83: 832-840, 1998.

17. Yao JS, Chen Y, Zhai W, Xu K, Young WL and Yang GY: Minocycline exerts multiple inhibitory effects on vascular endothelial growth factor-induced smooth muscle cell migration. Circ Res 95: 364-371, 2004.

18. Harada H, Nakagawa K and Iwata S: Restoration of wild-type p16 down-regulates vascular endothelial growth factor expression and inhibits angiogenesis in human gliomas. Cancer Res 59: 3783-3789, 1999.

19. Hofmann UB, Westphal JR, Van Kraats AA, Ruiter DJ and Van Muijen GN: Expression of integrin $\alpha v \beta 3$ correlation with activation of membrane-type matrix metalloproteinase-1 (MT1$\mathrm{mmp})$ and matrix metalloproteinase-2 (mmp-2) in human melanoma cells in vitro and in vivo. Int J Cancer 87: 12-19, 2000.

20. Zimmermann KC, Sarbia M, Weber AA, Borchard F, Gabbert HE and Schror K: Cycloxygenase-2 expression in human esophageal carcinoma. Cancer Res 59: 198-204, 1999.

21. Reddy KB, Krueger JS, Kondapaka SB and Diglio CA: Mitogenactivated protein kinase regulates the expression of proteintanase B (MMP-9) in breast epithelial cells. Int J Cancer 82: 268-273, 1999.

22. O'Charoenrat P, Rhys-Evans P, Modjtahedi H, Court W, Box G and Eccles $\mathrm{S}$ : Overexpression of epidermal growth factor receptor in human head and neck squamous carcinoma cell lines correlates with matrix metalloproteinases- 9 expression and in vitro invasion. Int J Cancer 86: 307-317, 2000.

23. Warren RS, Yuan H, Matli MR, Gillett NA and Ferrara N: Regulation by vascular endothelial growth factor of human colon cancer tumorigenesis in a mouse model of experimental liver metastasis. J Clin Invest 95: 1789-1797, 1995.

24. Rodriguez GC, Haisley C, Hurteau J, Moser TL, Whitaker R, Bast RC Jr and Stack MS: Regulation of invasion of epithelial ovarian cancer by transforming growth factor- $\beta$. Gynecol Oncol 80: 245-253, 2001. 
25. Dvorak HF, Brown LF, Detmar M and Dvorak AM: Vascular permeability factor/vascular endothelial growth factor, microvascular hyperpermeability, and angiogenesis. Am J Pathol 46: 1029-1039, 1995.

26. Oehler MK and Caffier H: Prognostic relevance of serum vascular endothelial growth factor in ovarian cancer. Anticancer Res 20: 5109-5112, 2000.

27. Schuch G, Heymach JV, Nomi M, et al: Endostatin inhibits the vascular endothelial growth factor-induced mobilization of endothelial progenitor cells. Cancer Res 63: 8345-8350, 2003.

28. Hayashibara T, Yamada Y, Miyanishi T, et al: Vascular endothelial growth factor and cellular chemotaxis: a possible autocrine pathway in adult $\mathrm{T}$ cell leukemia cell invasion. Clin Cancer Res 7: 2719-2726, 2001

29. Ueda M, Terai Y, Kumagai K, Ueki K, Yamaguchi H, Akise D and Ueki M: Vascular endothelial growth factor $\mathrm{C}$ gene expression is closely related to invasion phenotype in gynecological tumor cells. Gynecol Oncol 82: 162-166, 2001.

30. Lamoreaux WJ, Fitzgerald MC, Reiner A, Hasty KA and
Charles ST: Vascular endothelial growth factor increases release of gelatinase $\mathrm{A}$ and decrease release of tissue inhibitors of metalloproteinases by microvascular endothelial cells in vitro. Microvasc Res 55: 29-42, 1998.

31. Rooprai HK, Rucklidge GJ, Panou C and Pilkington GJ: The effects of exogenous growth factors on matrix metalloproteinase secrection by human brain tumor cells. Br J Cancer 82: 52-55, 2000.

32. Unemori EN, Ferrara N, Bauer EA and Amento EP: Vascular endothelial growth factor induces interstitial collagenase expression in human endothelial cells. J Cell Physiol 153: 557-562, 1992.

33. Hesling C, D'Incan M, Mansard S, et al: In vivo and in situ modulation of the expression of genes involved in metastasis and angiogenesis in a patient treated with topical imiquimod for melanoma skin metastases. Br J Dermatol 150: 761-767, 2004. 